\title{
A systematic study of the brain base arteries in the rabbit (Oryctolagus cuniculus) ${ }^{1}$
}

\author{
Fernanda de Souza ${ }^{2 *}$ and Rui Campos ${ }^{2,3}$
}

\begin{abstract}
Souza F. \& Campos R. 2013. A systematic study of the brain base arteries in the rabbit (Oryctolagus cuniculus). Pesquisa Veterinária Brasileira 33(6):796-806. Setor de Anatomia Animal, Faculdade de Medicina Veterinária, Universidade Federal do Rio Grande do Sul, Avenida Bento Gonçalves 9090, Porto Alegre, RS 91540-000, Brazil. E-mail: fesouzavet@yahoo.com.br

The brains of 30 New Zealand rabbits (Oryctolagus cuniculus) were injected with red stained latex. The arteries of the ventral surface of the brain were systematized on the right $(\mathrm{R})$ and on the left (L) side with the respective percentage of appearance: the aortic arch emitted the braquicephalic trunk and the left subclavian artery (83.3\%); or the braquicephalic trunk, the left common carotid artery and the left subclavian artery (16.7\%). The braquicephalic trunk emitted the right and the left common carotid arteries and the right subclavian artery (83.3\%); or the right common carotid artery and the right subclavian artery $(16.7 \%)$. The common carotid arteries were divided into external and internal carotid arteries $(96.7 \%$ on the $\mathrm{R}, 100 \%$ on the $\mathrm{L}$.). The internal carotid artery to the $\mathrm{R}$ was present (96.7\%) and absent (3.3\%), and to the L, was present (100\%). The rostral choroidal artery to the $\mathrm{R}$ was collateral branch of the rostral branch of the internal carotid artery $(83.3 \%)$, collateral branch of caudal branch of the internal carotid artery (16.7\%), and to the L was collateral branch of the rostral branch of the internal carotid artery (93.3\%), collateral branch of the caudal branch of the internal carotid artery (6.7\%). The middle cerebral artery to the $\mathrm{R}$ and to the $\mathrm{L}$ was single $(80 \%)$ and double $(20 \%)$. The rostral cerebral artery to the R had middle caliber (90\%), thin caliber (6.7\%) and too thin caliber (3.3\%), and to the L had middle caliber $(76.7 \%)$, thin caliber $(16.7 \%)$ and too thin caliber $(6.7 \%)$. The internal ethmoidal artery was absent (73.3\%), present and single (26.7\%). The caudal cerebral artery to the R was single (66.7\%), double (26.7\%) and triple (6.7\%), and to the L was single $(63.3 \%)$ and double (36.7\%). The terminal branches of the right and left vertebral arteries were present $(100 \%$, and formed the basilar artery $(100 \%)$. The ventral spinal artery was present $(100 \%)$. The caudal cerebellar artery, to the R was single $(43.3 \%)$, single with labyrinthic artery isolated $(26.7 \%)$ and double $(30 \%)$, and to the L was single (50\%), single with labyrinthic artery isolated (6.7\%), double (40\%) and triple (3.3\%). The trigeminal artery to the $\mathrm{R}$ and to the $\mathrm{L}$ was present $(100 \%)$. The rostral cerebellar artery to the $\mathrm{R}$ was single $(53.3 \%)$ and double $(46,7 \%)$, and to the $\mathrm{L}$ was single $(63.3 \%)$ and double $(36.7 \%)$. The rabbit's cerebral arterial circle was caudally closed (100\%) and rostrally closed (93.3\%) or opened (6.7\%). The brain was supplied by the vertebral-basilar and carotid systems.
\end{abstract}

INDEX TERMS: Brain vascularization, cerebral arteries, Oryctolagus cuniculus, rabbit.

\footnotetext{
${ }^{1}$ Received on September 3, 2012.

Accepted for publication on April 17, 2013.

${ }^{2}$ Programa de Pós-Graduação em Ciências Veterinárias (PPGCV), Faculdade de Veterinária, Universidade Federal do Rio Grande do Sul (UFRGS), Av. Bento Gonçalves 9090, Bairro Agronomia, Porto Alegre, RS 91540-000, Brazil.*Corresponding author: fesouzavet@yahoo.com.br

${ }^{3}$ Laboratório de Anatomia Animal, Departamento de Ciências Morfológicas, Instituto de Ciências Básicas da Saúde (ICBS), UFRGS, Av. Bento Gonçalves 9090, Bairro Agronomia, Porto Alegre, RS. E-mail: rcampos@ufrgs.br
}

RESUMO.- [Sistematização das artérias da base do encéfalo e suas fontes de suprimento sanguíneo em coelho da raça Nova Zelândia (Oryctolagus cuniculus).] Foram utilizados 30 encéfalos de coelhos Nova Zelândia (Oryctolagus cuniculus), injetados com látex, corado em vermelho, com objetivo de sistematizar as artérias da base do encéfalo e suas fontes de suprimento sanguíneo. Sistematizou-se a origem das fontes de suprimento sanguíneo para o en- 
céfalo e as artérias (Aa) da face ventral do mesmo, tanto à direita (D) como à esquerda (E), com suas respectivas percentagens de aparecimento: o arco aórtico emitiu tronco braquiocefálico e artéria (A.) subclávia E (83,3\%), ou tronco braquiocefálico, A. carótida comum E e A. subclávia E (16,7\%). 0 tronco braquiocefálico lançou A. carótida comum D e E e A. subclávia D (83,3\%), ou A. carótida comum D e A. subclávia D (16,7\%). A. carótida comum dividiu-se em Aa carótidas externa e interna $(96,7 \%$ D, $100 \%$ E). A. carótida interna D presente $(96,7 \%)$ e ausente $(3,3 \%)$, à $\mathrm{E}$ presente (100\%). A. corióidea rostral D ramo colateral do ramo rostral da A. carótida interna $\mathrm{D}(83,3 \%)$, ramo colateral do ramo caudal da A. carótida interna D (16,7\%), à $\mathrm{E}$, ramo colateral do ramo rostral da A. carótida interna $\mathrm{E}$ $(93,3 \%)$, ramo colateral do ramo caudal da A. carótida interna E (6,7\%). A. cerebral média D e E ímpar (80\%) e dupla (20\%). A. cerebral rostral D com calibre médio (90\%), calibre fino $(6,7 \%)$, calibre muito fino $(3,3 \%)$, à E, com calibre médio $(76,7 \%)$, calibre fino $(16,7 \%)$, calibre muito fino $(6,7 \%)$. A. etmoidal interna ausente $(73,3 \%)$, presente e ímpar $(26,7 \%)$. A. cerebral caudal D, ímpar $(66,7 \%)$, dupla $(26,7 \%)$ e tripla $(6,7 \%)$, à E, ímpar $(63,3 \%)$ e dupla $(36,7 \%)$. Ramos terminais das Aa. vertebrais D e E presentes $(100 \%)$ formaram a A. basilar (100\%). A. espinhal ventral ímpar presente (100\%). A. cerebelar caudal D, ímpar (43,3\%), ímpar com A. labiríntica isolada $(26,7 \%)$ e dupla (30\%), à E, ímpar (50\%), ímpar com A. labiríntica isolada $(6,7 \%)$, dupla (40\%) e tripla (3,3\%). A. trigeminal D e E presente $(100 \%)$. A. cerebelar rostral D, ímpar $(53,3 \%)$ e dupla (46,7\%), à E, ímpar (63,3\%) e dupla $(36,7 \%)$. Observou-se que o círculo arterial Cerebral do coelho foi fechado caudalmente $(100 \%)$, rostralmente fechado $(93,3 \%)$ e aberto $(6,7 \%)$. 0 encéfalo foi suprido pelos sistemas vértebro-basilar e carotídeo.

TERMOS DE INDEXAÇÃO: Vascularização encefálica, artérias cerebrais, Oryctolagus cuniculus, coelho.

\section{INTRODUCTION}

The domestic rabbit (Oryctolagus cuniculus) is a lagomorph of the Leporidea family. It is widely used as an experimental animal; however, vascular brain studies about this species are rare.

There have been very few studies about the lagomorph brain's blood supply. The classic studies by Tandler (1898) and De Vriese (1905) provided important contributions to the phylogeny and ontogeny of the cerebral arteries.

In addition, there were some descriptions about the cerebral vascularization in dogs (Alcântara 1992), chickens (Campos et al. 1995), swine (Ferreira 1998), opossum (Lindemann et al. 2000), capybara (Reckziegel, et al. 2001), pampa fox (Depedrini \& Campos 2003), chinchilla (Araújo \& Campos 2005), nutria (Azambuja 2006), ostrich (Nazer \& Campos 2011) and turkey (Carvalho \& Campos 2011). Few studies have also examined the cerebral blood supply in rabbits (O. cuniculus) (Freisenhausen 1965, Lazorthes et al. 1976, Casals et al. 2011).

This study aims to systematize the brain's base arteries of the rabbit (Oryctolagus cuniculus), describing a standard model of irrigation and the main variations, in this species. This information will contribute to the studies in this area of the comparative anatomy about the phylogenetic development of the blood supply to the central nervous system.

\section{MATERIALS AND METHODS}

Thirty brains, along with the spinal cord segment, thorax, neck and head, of young adult rabbits (Orycytolagus cuniculus), 14 males and 16 females, were used in this study. The animals were obtained from a breeder located in Novo Hamburgo, in the state of Rio Grande do Sul, Brazil.

The animals were contained and euthanized with $3 \mathrm{ml} / \mathrm{ani}-$ mal of T 61, via intrapulmonary. After, the skin was removed, the thoracic cavity opened and the thoracic aorta was cannulated in counterflow. Both cranial venas cavas and the caudal vena cava were sectioned close to the heart. The arterial system was washed with cold $0.9 \%$ saline solution mixed with 5000 IU heparin $(120 \mathrm{ml} / \mathrm{animal})$ and the system was filled with latex injection, coloured with red pigment. The samples remained for a least one hour under running water for latex polymerization. The trunk was then sectioned close to the last thoracic vertebra. A window was opened in the skullcap, and pieces were fixed in $20 \%$ formaldehyde for seven days. After, the brains were removed with a cervical spinal cord segments. The main and collateral branches of the aortic arch were dissected to allow description of the vessels that supplied blood to the brain.

Schematic drawings of the brain's base arteries and of the collateral branches of the aortic arch were prepared with the aid magnifying glass ${ }^{4}$. The vessels were named according to the Nomina Anatomica Veterinaria (2005), with some designations based on the author's interpretation of previous reports. Some specimens were photographed to illustrate the documentation.

The occurrence of the vessels was expressed as the percentage of a total number of 30 brain samples examined.

This study, number 19383, was approved by Comissão de Ética na Utilização de Animais (CEUA), of Universidade Federal do Rio Grande do Sul, in September 30, 2010.

\section{RESULTS}

The rabbit's brain was vascularized by the internal carotid and vertebral arteries, where these two systems cooperated equally. Regarding the sources of blood supply for the rabbit's brain, in $83.3 \%$ of the cases, the aortic arch emitted the brachycephalic trunk and the left subclavian artery, but in $16.7 \%$ of the samples emitted the brachycephalic trunk, the left common cartotid artery and the left subclavian artery. The subclavian artery, branch of the brachycephalic trunk to the right and of the aortic arch to the left, was laterally projected and emerged from the thoracic cavity, cranially to the first rib and emitted, in this course, a sequence of collateral branches, among them the vertebral artery, in all preparations. The vertebral artery was cranially projected from the thorax and penetrated in the cervical transversal canal from the sixth cervical vertebra, until it reached the atlas, where it bordered the alar incisure and entered into the vertebral canal, through the lateral vertebral foramen, towards the cranian cavity, though the foramen magnum. But the common carotid artery ascended to the neck and laterally followed the trachea, until it reached the base

\footnotetext{
${ }^{4}$ LTS illuminated magnifier with a 5x magnification, Stemi SV8 Zeiss, Göttingen, Germany.
} 
of the brain. At the level of the hypoglossus nerve's loop, it was divided into an internal carotid artery, which participated in the vascularization of the brain, continued as external carotid artery, which distributed its branches into the face. In $3.3 \%$ of the findings, the right internal carotid artery was absent as a branch of the right common carotid artery, but was substituted by a branch originated from the left internal carotid artery, at the level of the hypophysis (Fig.1).

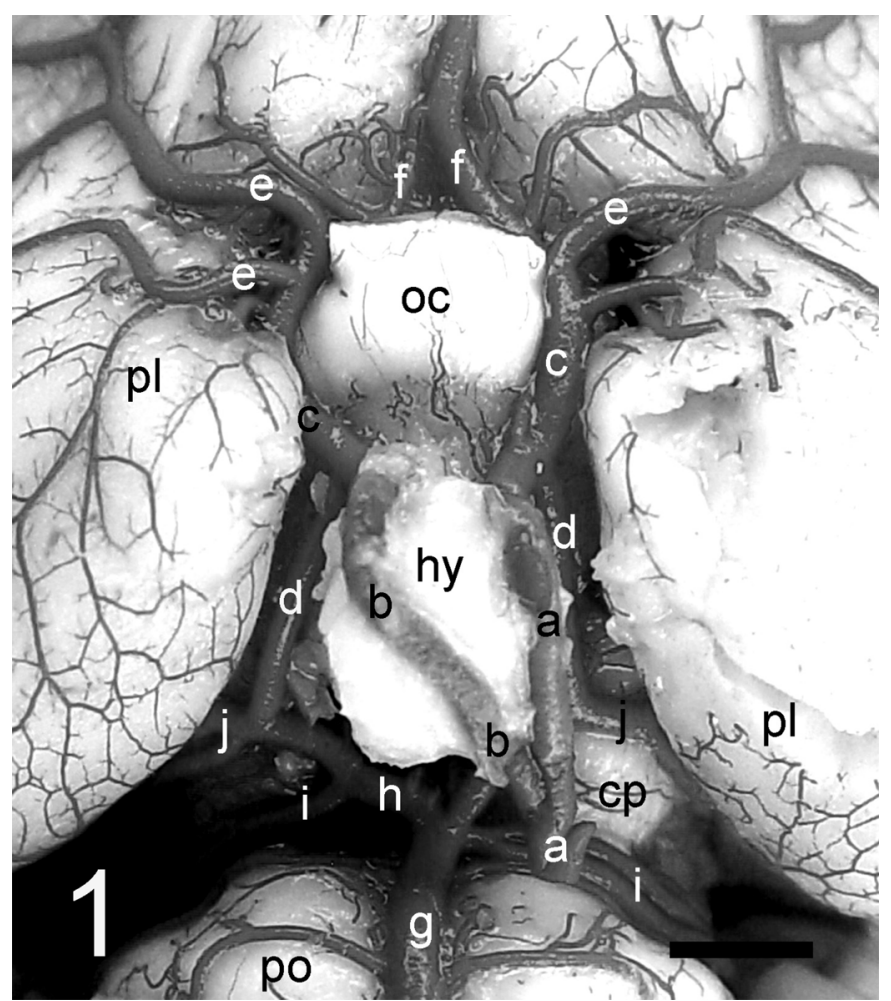

Fig.1. Detailed ventral view of the rabbit's brain (Obs. 3), showing the absence of the right internal carotid artery: (a) left internal carotid artery; (b) branch of the left internal carotid artery (right internal carotid artery); (c) rostral branch of internal carotid artery; (d) caudal branch of internal carotid artery; (e) middle cerebral artery; (f) rostral cerebral artery; (g) basilar artery; (h) right terminal branch of the basilar artery; (i) rostral cerebellar artery; (j) caudal cerebral artery; (oc)optic chiasm; (pl) pyriform lobe; (hy) hypophysis; (cp) cerebral peduncle; (po) pons. Bar $=2.2 \mathrm{~mm}$.

Regarding the base brain's arteries, the internal carotid artery (arteria carotis interna), branch of the common carotid artery, entered into the cranial cavity, by the carotid foramen. It was projected rostrally until reached the hypophysis, laterally, and rostrally projected dorsally until reached the tuber cinereum. It divided into its terminal branches, the rostral branch and the caudal branch (caudal communicating artery). In $3.3 \%$ of the samples to the right, the internal carotid artery, at the level of the cerebral peduncles, emitted a thick caliber vessel, which anastomosed with the terminal part of the basilar artery and originated the right rostral cerebellar artery.

The rostral branch of the internal carotid artery was projected rostrally until it reached the optic chiasm, whe- re laterally emitted, besides its larger collateral branch, the middle cerebral artery, also the internal ophthalmic artery, the rostral choroidal artery and central branches to the medial part of the pyriform lobe. Rostromedially the rostral branch of the internal carotid artery continued as its terminal branch, the rostral cerebral artery (Fig.2 and 3).

The internal ophthalmic artery (a. ophthalmica inter$n a)$, a middle caliber vessel, was a collateral branch of the rostral branch of the internal carotid artery in $53.3 \%$ of the cases to the right and $50 \%$ to the left, and collateral branch of the caudal branch (caudal communicating artery) of the internal carotid artery in $46.7 \%$ of the findings to the

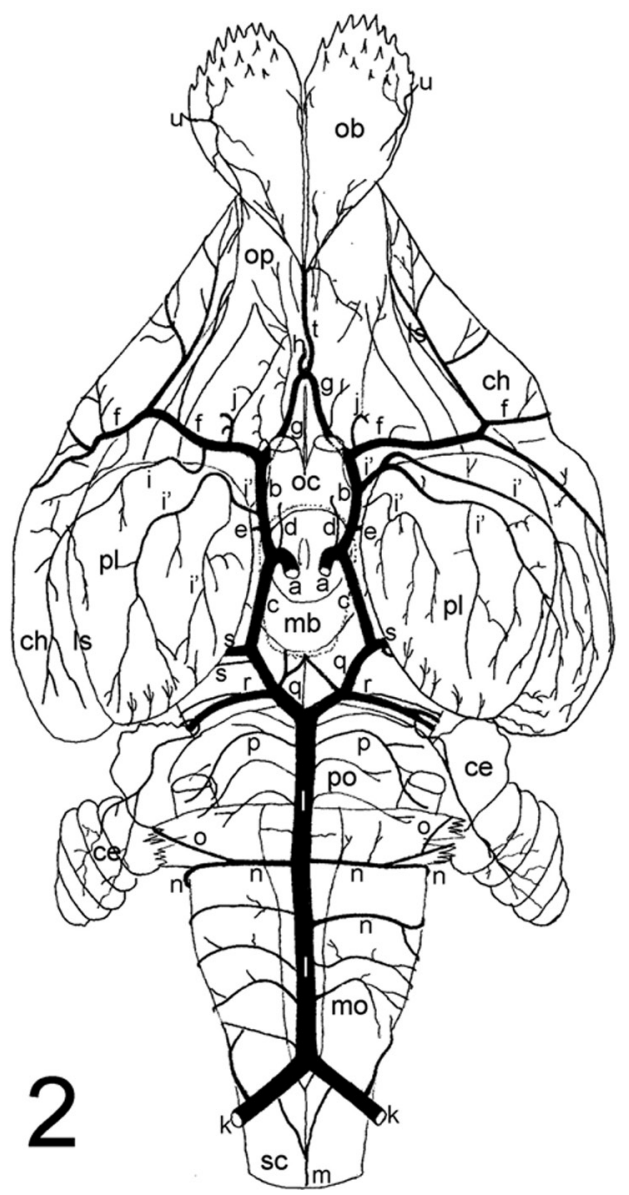

Fig.2. Schematic drawing of ventral view of the rabbit's brain (Obs. 1), without hypophysis, highlighting major appearances of the base vessel, standard model: (a) internal carotid artery; (b) rostral branch of internal carotid artery; (c) caudal branch of internal carotid artery; (d) internal ophthalmic artery;(e) rostral choroidal artery; (f) middle cerebral artery; (g) rostral cerebral artery; (h) rostral communicating artery; (i) caudal central branches of f; (i') central branches of the rostral branch of a; (j) rostral central branches of f; (k) vertebral artery; (l) basilar artery; (m) ventral spinal artery; (n) caudal cerebellar artery; (o) labirintic artery; (p) trigeminal artery; (q) terminal branch of the basilar artery; (r) rostral cerebellar artery; (s) caudal cerebral artery; (t) internal ethmoidal artery; $(\mathrm{u})$ external ethmoidal artery; (ob) olfactory bulb; (op) olfactory peduncles; (ls) lateral rhinal sulcus; (ch) cerebral hemisphere; (oc)optic chiasm; (pl) pyriform lobe; (mb) mamillary body; (ce) cerebellum; (po) pons; (mo) medulla oblongata; (sc) spinal cord. 


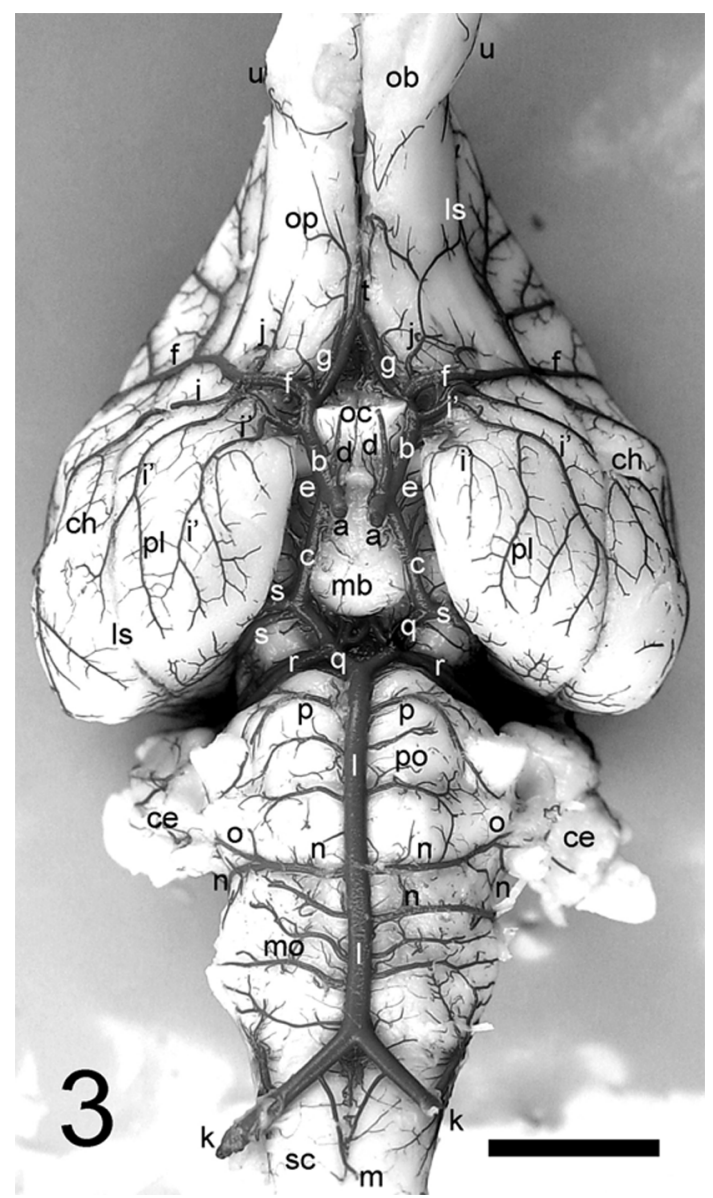

Fig.3. Ventral view of the rabbit's brain (Obs.1), without hypophysis, highlighting major appearances of the base vessel, standard model: (a) internal carotid artery; (b) rostral branch of internal carotid artery; (c) caudal branch of internal carotid artery; (d) internal ophthalmic artery;(e) rostral choroidal artery; (f) middle cerebral artery; (g) rostral cerebral artery; (i) caudal central branches of f; (i') central branches of the rostral branch of a; (j) rostral central branches of $\mathrm{f}$; (k) vertebral artery; (l) basilar artery; (m) ventral spinal artery; (n) caudal cerebellar artery; (o) labirintic artery; (p) trigeminal artery; (q) terminal branch of the basilar artery; (r) rostral cerebellar artery; (s) caudal cerebral artery; ( $\mathrm{t}$ ) internal ethmoidal artery; (u) external ethmoidal artery; (ob) olfactory bulb; (ls) lateral rhinal sulcus; (op) olfactory peduncles; (oc) optic chiasm; (ch) cerebral hemisphere; (pl) pyriform lobe; (mb) mamillary body; (po) pons; (ce) cerebellum; (mo) medulla oblongata; (sc) spinal cord. Bar $=6 \mathrm{~mm}$.

right and $50 \%$ to the left. This artery was projected on the ventral surface of the optic chiasm, abandoned the cranial cavity, together with the optic nerve, through the homonymous foramen, and reached the orbital cavity and anastomosed with the external ophthalmic artery, branch of the maxillary artery.

But the rostral choroidal artery (a. choroidea rostralis) was a middle caliber vessel, which was projected from the rostral branch of the internal carotid artery in $83.3 \%$ of the samples to the right and $93.3 \%$ to the left, and from the caudal branch of the internal carotid artery (caudal communicating) in $16.7 \%$ of the cases to the right and $6.7 \%$ to the left. The rostral choroidal artery was projected into the interior of the cerebral transverse fissure, followed the optic tract until it reached the roof of the III ventricle and formed the choroid plexus of the same.

The rostral branch of the internal carotid artery also emitted, in most cases, from one to two central branches to the pyriform lobe, sharing the territorial area with the caudal central branches of the middle cerebral artery (Fig.2 and 3). The central branches of the rostral branch of the internal carotid artery vascularized, sometimes, only a small and more medial area of the territory, or half of it, or even the entire pyriform lobe, due to the absence of the caudal central branches of the middle cerebral artery of the same antimere. But in $20 \%$ of the findings to the right and in $23.3 \%$ to the left, the rostral branch of the internal carotid artery did not present a central branch and the territory of the pyriform lobe was vascularized by the caudal central branches of the middle cerebral artery.

The middle cerebral artery (a. cerebri media), main collateral branch of the rostral branch of the internal carotid artery, was laterally projected, through the interior of cerebral lateral fossa, towards the convex surface of the cerebral hemisphere and ramified in a divergent arborescence (Fig.2-4). It vascularized, from the occipital pole to the frontal pole of the cerebral hemisphere, except for a small zone between the two poles, which border all the extension of the cerebral longitudinal fissure. Its terminal branches anastomosed in osculum with the terminal branches of the rostral medial hemispheric arteries, branches of the branches of the rostral cerebral artery. However, in the occipital pole of the cerebral hemisphere, the terminal branches of the middle cerebral artery anastomosed with the terminal branches of the caudal medial hemispheric arteries, from the caudal cerebral artery. On the trajectory of the middle cerebral artery, between the optic chiasm and the lateral rhinal sulcus, the main axis emitted to the cerebral lateral fossa and olfactory trigonous perforating and rostral cen-

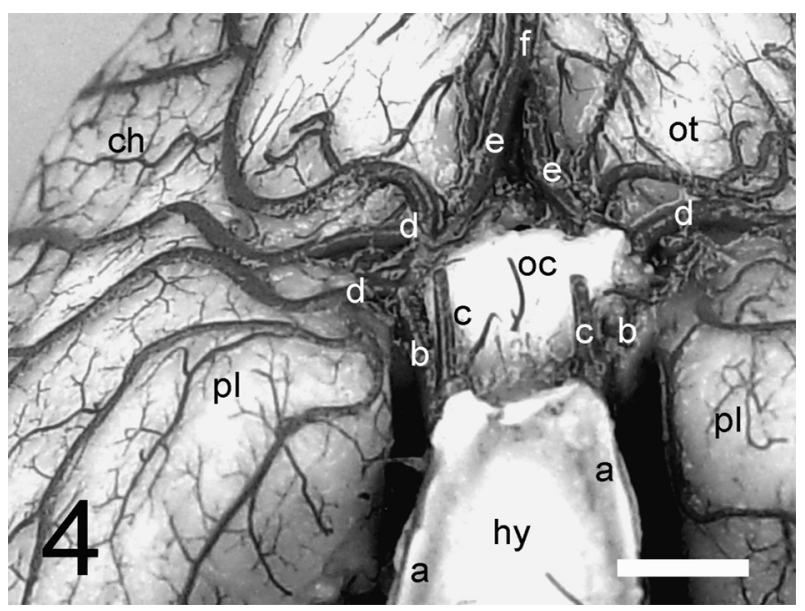

Fig.4. Detailed ventral view of the rabbit's brain (Obs.30) to highlight the duplicity to the right middle cerebral artery: (a) internal carotid artery; (b) rostral branch of internal carotid artery; (c) internal ophthalmic artery; (d) middle cerebral artery; (e) rostral cerebral artery; (f) rostral communicating artery; (ch) cerebral hemisphere; (ot) olfactory trigonous; (oc) optic chiasm; (pl) pyriform lobe; (hy) hypophysis. Bar $=3 \mathrm{~mm}$. 
tral branches. Also emitted caudal central branches to the pyriform lobe and shared this territory with the central branches of the rostral branch of the internal carotid artery, in the most of the samples. When the middle cerebral artery was double (20\% of the cases to the right and left) (Fig.4), the first component of it to be emitted from the rostral branch of the internal carotid artery, despite emitting all of the caudal central branches, it surpassed the lateral rhinal sulcus (sulcus rhinalis lateralis) and vascularized a large caudal area of the convex surface of the cerebral hemisphere.

The rostral cerebral artery (a. cerebri rostralis), a median caliber vessel and terminal branch of the rostral branch of the internal carotid artery, was projected from the origin of the middle cerebral artery, mediorostrally, overpassed the optic nerve and reached the cerebral longitudinal fissure ventrally, where it anastomosed with its contralateral homologous and formed a single, rostral and median communicating artery (Fig.2). The rostral cerebral artery ascended towards the corpus callosum, bifurcated just before it reached its knee and originated the left and right rostral inter-hemispheric arteries. The rostral inter-hemispheric arteries were caudally projected over the corpus callosum, until it reached its splenium and anastomosed with the terminal branch of the caudal inter-hemispheric artery. The rostral inter-hemispheric artery emitted, sequencially, several rostral medial hemispheric branches, which vascularized the medial surface of the cerebral hemisphere and also reached a small longitudinal area of the convex surface, where its terminal branches anastomosed "in osculum" with the terminal branches of the middle cerebral artery. In $6.7 \%$ of the findings, the rostral communicating artery did not properly formed an individual vessel, but a contact-like anastomosis, which continued on both right and left rostral inter-hemispheric arteries. While in $6.7 \%$ of the brains, the rostral communicating artery was a fine caliber vessel that linked the two rostral cerebral arteries, so that in one case it was formed by the anastomosis of two branches and in another was an obliquous vessel. In $6.7 \%$ of the cases, there was no formation of the rostral communicating artery and the cerebral arterial circle remained rostrally opened. In one of these cases, each rostral cerebral artery formed a rostral inter-hemispheric artery on its antimere (Fig.5). But, in another finding, the right rostral cerebral artery, after penetrating the cerebral longitudinal fissure, bifurcated and formed the right and left rostral inter-hemispheric arteries, while the left rostral cerebral artery was rostrally projected on the ventral surface of the cerebral hemisphere, until it reached the olfactory bulb.

The internal ethmoidal artery (a. ethmoidalis interna) was, in the most of the cases, an absent vessel (73.3\%), and the entire olfactory bulb was vascularized by the external ethmoidal artery, a branch of the maxillary artery, which penetrated through the ethmoidal foramen. When present (26.7\%), the internal ethmoidal artery was a single vessel, of fine caliber, originated from the rostral communicating artery, bifurcated into both antimeres, vascularizing part of the olfactory peduncle and the medial surface of the olfactory bulb (Fig.2 and 3). The lateral and medial arteries of

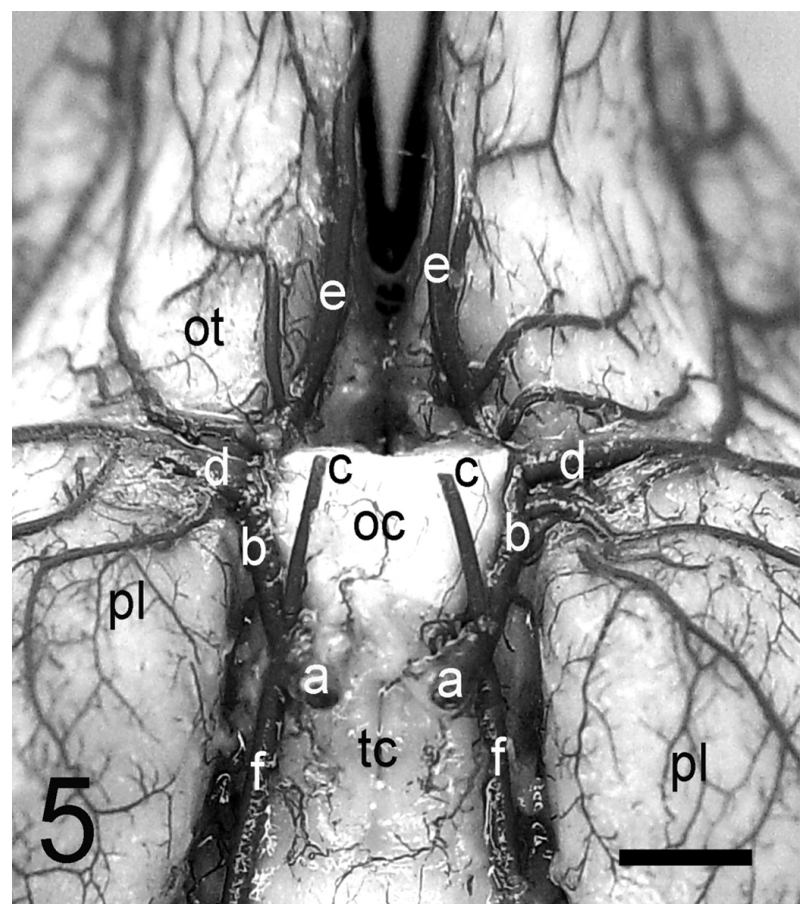

Fig.5. Detailed ventral view of the rabbit's brain (Obs.25) to highlight the cerebral arterial circle opened rostrally: (a) internal carotid artery; (b) rostral branch of internal carotid artery; (c) internal ophthalmic artery; (d) middle cerebral artery; (e) rostral cerebral artery; (f) caudal branch of internal carotid artery; (ot) olfactory trigonous; (oc) optic chiasm; (pl) pyriform lobe; (tc) tuber cinereum. Bar= $2 \mathrm{~mm}$.

the olfactory bulb, originated from the rostral communicating artery, were very thin vessels that reached the olfactory peduncle and a small part of the olfactory bulb's base.

The terminal branch of the internal carotid artery (caudal communicating artery)(a. communicans caudalis), a median caliber vessel, was projected caudally with a slight lateral divergence, following the medial border of the pyriform lobe until it reached the terminal branch of the basilar artery of the same antimere, at the level of the caudal border of the mammillary body. From the anastomosis of the caudal branch of the internal carotid artery (caudal communicating artery) with the terminal branch of the basilar artery, the caudal cerebral artery was formed (Fig.2 and 3).

The caudal cerebral artery (a. cerebri caudalis) was laterally projected into the interior of the cerebral transverse fissure, and emitted central branches to the caudomedial part of the pyriform lobe. Next, it originated the rostral tectal artery to the rostral colliculus and rostral part of the caudal colliculus. Also emitted the diencephalic artery, and to follow the dentate gyrus, as the caudal inter-hemispheric artery. This last, originated a sequence of caudal medial hemispheric branches to the mediocaudal cerebral hemisphere's surface. Its terminal branch bordered the splenium of the corpus callosum, anastomosed with the terminal branch of the rostral inter-hemispheric artery. The caudal cerebral artery was presented as a single vessel (66.7\% to the right and $63.3 \%$ to the left), double $(26.7 \%$ to the right and $36.7 \%$ to the left) and even triple $(6.7 \%$ to the right). In cases of duplicity, in both antimeres, the most 
caudal component was the isolated rostral tectal artery (Fig.2 and 3) or a trunk, which originated the rostral tectal and the diencephalic arteries. But in cases of triplicity, in one finding, the formation of two rostral tectal arteries occurred, and in another, the most caudal component was the rostral tectal artery and the intermediate component was the diencephalic artery, both isolated.

Another blood supply source to the rabbit's brain was the vertebral artery, a thick caliber vessel, which was originated from the subclavian artery of the same antimere. The right and left vertebral arteries ( $a$. vertebralis), when entered the foramen magnun, anastomosed at the ventral median line of the medulla oblongata and formed rostrally a basilar artery, of thick caliber. Fine branches were caudally projected from the vertebral arteries and formed the ventral spinal artery (Fig.2 and 3).

The ventral spinal artery (a. spinalis ventralis) was presented as a thin caliber vessel, formed by the branches of the right and left vertebral arteries in $90 \%$ of the cases (Fig.2 and 3), by branches of the left vertebral artery in $6.7 \%$ and by branches of the right vertebral artery in 3.3\%.

The basilar artery ( $a$. basilaris), a median vessel, single and of thick caliber, was originated from the anastomosis between the right and left vertebral arteries. It was rostrally projected in a straight path, following the ventral median fissure of the medulla oblongata, until it surpassed the pons, where it was divided into its terminal branches, right and left (Fig.2 and 3). The basilar artery was presented "in island" formation in its origin, in $16.7 \%$ of the findings. And in one of these samples, it also occurred a second "in island" formation, close to its terminal end.

The most rostral third of the medulla oblongata was vascularized by thin collateral branches of the basilar artery, and the same occurred with vascularization of the pons. The more important vessels for the cerebellum and the choroid plexus of the IV ventricule were: the caudal cerebellar arteries with their labyrinthic branch and the trigeminal artery to the trigeminal nerve and its ganglion.

The caudal cerebellar artery (a. cerebelli caudalis), a frequently single vessel, projected laterally from the basilar artery at the level of the caudal border of the trapezoid body. It emitted the labyrinthic artery (a. labyrinthi) to the internal ear, continuing dorsally until it reached the choroid plexus of the IV ventricle and the caudoventral lobulus of the cerebellum. When single, the caudal cerebellar artery emitted the labyrinthic artery in $43.3 \%$ to the right (Fig.2 and 3) and 50\% to the left. But in $26.7 \%$ to the right and $6.7 \%$ to the left, the labyrinthic artery was emitted isolated and directly from the basilar artery. There were also cases of duplicity (30\% to the right and $40 \%$ to the left) (Fig.2 and 3) and triplicity (3.3\% to the left) of the caudal cerebellar artery.

The trigeminal artery ( $a$. trigeminalis), a thin caliber vessel, was a branch of the basilar artery, emitted for the trigeminal nerve and its ganglion in both antimeres, close to the terminal branches, ventrally to the pons (Fig.2 and 3 ). In all samples to the right and in $93.3 \%$ to the left, the trigeminal artery presented its origin in a standard pattern. However, in $6.7 \%$ of the cases to the left, the trigeminal ar- tery presented a variation in its origin: in one finding the origin was a branch of the thin caliber portion of the "in island" formation of the basilar artery; but on the other sample, the origin of the trigeminal artery was in the atypical rostral cerebellar artery.

After it reached the sulcus that separates the pons of the cerebral peduncles, the basilar artery divided into its terminal branches, right and left, in a divergent angle approximately of $\pm 90^{\circ}$, to anastomose with the caudal branch of the internal carotid artery (caudal communicating artery) and formed together with this, the caudal cerebral artery, medially juxtaposed to the pyriform lobe (Fig.2 and 3). Its main collateral branch, the rostral cerebellar artery, was projected into the interior of the cerebral transverse fissure and vascularized the caudal colliculus and the entire cerebellum.

In the majority of the samples, the terminal branches of the basilar artery presented a standard pattern (Fig.2 and 3 ). However, in $13.3 \%$ of the cases to the right and in $3.3 \%$ to the left, the terminal branches were altered. To the right, in one finding, the right terminal branch did not originate its usual collateral branch, the rostral cerebellar artery, and this was originated from the terminal part of the basilar artery. In another case, the left terminal branch of the basilar artery was presented very thin, due to the presence of a large anastomosis between the right internal carotid artery and the terminal part of the basilar artery. But to the left, the left rostral cerebellar artery was emitted from the basilar artery at the level of the pons and made an anastomosis with the vessel descendant from the left terminal branch of the basilar artery.

The rostral cerebellar artery (a. cerebelli rostralis), a large caliber vessel, was presented normally double in the right antimere and single in the left antimere. When double, the main vessel vascularized almost the entire cerebellum, except for the caudal colliculus. While its second component, the caudal tectal artery, was emitted directly from the terminal branch of the basilar artery, closely rostrally to the main vessel, vascularizing the caudal colliculus $(53.3 \%$ to the right and $36.7 \%$ to the left). To the right, in one finding, the main vessel of the right rostral cerebellar artery was originated from the basilar artery; while in another case, the right caudal tectal artery was originated isolated from the thin right terminal branch of the basilar artery. When single, the caudal tectal artery was a branch of the rostral cerebellar artery ( $46.7 \%$ to the right and $63.3 \%$ to the left) (Fig.2 and 3). And in one case, to the right, the right rostral cerebellar artery was a branch originated directly from the basilar artery. In another case, the left rostral cerebellar artery was originated from the basilar artery, at the level of the pons.

The arterial circle of the rabbit's brain formed an irregular geometric figure, rostrally involving the base of the optic nerves, the optic chiasm, the tuber cinereum and caudally the mammilary body and the interpeduncular fossa. It was extended from the cerebral longitudinal fissure at the level of the olfactory trigonous' base until the sulcus that separates the pons of the cerebral peduncles. The vessels which delimited it were: rostrally, rostral branch of the in- 
ternal carotid artery, rostral cerebral arteries and rostral communicating artery; and caudally, the caudal branches of the internal carotid artery (caudal communicating artery) and the terminal branches of the basilar artery. In all brains, the cerebral arterial circle was caudally closed (Fig.2 and 3 ). In $93.3 \%$ of the cases, the cerebral arterial circle was rostrally closed, generally by the formation of a single median artery, the rostral communicating artery. However, in $6.7 \%$, the rostral communicating artery was absent, leaving the cerebral arterial circle rostrally opened (Fig.5).

The cerebral arterial vascularization of the rabbit was supplied by two systems, the vertebrobasilar and the carotid, fitting on Type II, subtype alpha, with beta tendency of DeVriese (1905).

\section{DISCUSSION AND CONCLUSIONS}

According to Barone (1996), the rabbit's aorta was originated from the left ventricle, projected craniodorsolaterally to the left and formed the aortic arch. Angell-James (1974), Albuquerque et al. (1987) and Barone (1996) in their studies with rabbits, reported that the aortic arch originated, in sequence, the brachycephalic trunk and the left subclavian artery, in most of the findings. While in the minority of the animals, the collateral branches of the aortic arch was the brachycephalic trunk, the left common carotid artery and the left subclavian artery. These same findings were reported by Oliveira et al. (2001) in paca, Kabak \& Haziroglu (2003) in guinea-pig, Araújo et al. (2004) in chinchilla, Magalhães et al. (2007) in rock cavy and the same was observed in rabbits in this study. But Atalar et al. (2003) described the presence of three vessels originated from the aortic arch in the Brazilian porcupine, that is, the brachycephalic trunk and the left common carotid and left subclavian arteries. And in seven capybaras on the study of Culau et al. (2007), the aortic arch was originated only from the brachycephalic trunk.

To Angell-James (1974) and Barone (1996), the brachycephalic trunk of the rabbit emitted the left carotid artery and, soon after, a right carotid artery, continuing to the right as right subclavian artery. However, for Albuquerque et al. (1987) in the rabbit, Oliveira et al. (2001) in paca, Kabak \& Haziroglu (2003) in guinea-pig, Araújo, Oliveira \& Campos (2004) in chinchilla and Campos et al. (2010) in nutria, the brachycephalic trunk emitted, some millimeters after its origin, a right common carotid artery and continued as right subclavian artery. In the study of Angell-James (1974), in rabbits, in 23 of their 31 cases, the brachycephalic trunk originated a innominate artery (from which the right carotid and right subclavian arteries were emitted) and left carotid artery. When the innominate artery was absent (3 cases), the brachycephalic trunk originated the right common carotid artery, the right subclavian artery and the left common carotid artery, such as found in the present study, in some cases.

The left subclavian artery was branch of the aortic arch, in agreement with the findings of Angell-James (1974), Albuquerque et al. (1987) and Barone (1996) in rabbits, Oliveira et al. (2001) in paca, Atalar et al. (2003) in the Brazilian porcupine, Kabak \& Haziroglu (2003) in guinea-pig,
Araújo et al. (2004) in chinchilla, Culau et al. (2007) in capybara, Magalhães et al. (2007) in rock cavy, and Campos et al. (2010) in nutria.

Albuquerque et al. (1987) in rabbit, Culau et al. (2007) in capybara, and Magalhães et al. (2007) in rock cavy described the presence of a bicarotid trunk, which originated the right and left carotid arteries, what has not been found in this study.

The vertebral artery was branch of the subclavian arteries, as well as for Angell-James (1974), Albuquerque et al. (1987) and Barone (1996), in rabbits, Oliveira et al. (2001) in paca, Atalar et al. (2003) in Brazilian porcupine, Kabak \& Haziroglu (2003) in guinea-pig, Araújo et al. (2004) in chinchilla, Culau et al. (2007) in capybara, Magalhães et al. (2007) in rock cavy and Campos et al. (2010) in nutria.

The common carotid arteries, skullcap's base and at the level of the hypoglossal nerve's loop, bifurcated into the external and internal carotid arteries, and the first went towards the face, and the second contributed to the irrigation of the brain in the rabbit (Barone 1996).

Regarding the blood supply to the brain, Tandler (1898) described the internal carotid artery as a primitive vessel, in constant development, in the entire mammalian series. According to the author, the internal carotid artery was obliterated in some species in a way that it was only observed as a thin fibrous cord, as in capybara (Reckziegel et al. 2001), or was even absent, as in chinchilla (Araújo \& Campos 2005), in nutria (Azambuja 2006) and in 3.3\% of the rabbits studied, where due to the absence of the right internal carotid artery, occurred, at the base of the hypophysis, the formation of a branch that substituted it, originated from the left internal carotid artery.

To De Vriese (1905), morphologically, the internal carotid artery was a primitive cerebral artery, divided in the cranial cavity into two terminal branches: rostral branch and caudal branch (caudal communicating artery), in agreement with the findings in the rabbit, where the rostral branch formed the middle cerebral artery, the internal ophthalmic artery, the rostral choroidal artery and central branches to the medial part of the pyriform lobe; and the caudal branch formed the caudal cerebral artery at the level of the caudal limit of the mammillary body.

Freisenhausen (1965) and Barone (1996) observed that, on the ventral surface of the optic chiasm in rabbits, the internal ophthalmic artery was a collateral branch of the rostral branch of the internal carotid artery, or collateral branch of the internal carotid artery, following the optic nerve until the orbitary cavity. This result is opposite to the findings of Reckziegel et al. (2001), which observed, in capybara, an anastomosis between the internal ophthalmic artery and the maxillary artery, with the internal ophthalmic artery being terminal branch of the terminal branch of the basilar artery. But to Araújo \& Campos (2005), the internal ophthalmic artery in chinchilla was an inconstant vessel in the majority of the samples, and when present it was single and collateral branch of the respective terminal branch of the basilar artery. While for Azambuja (2006), the internal ophthalmic artery, in nutria, was collateral branch of the rostral cerebral artery. In the study of Ocal \& 
Ozer (1992) in guinea-pigs, the internal ophthalmic artery was united with the maxillary artery by a thick caliber communicating artery; however, the internal carotid artery was exceptionally thin. This suggested that the prosencephalon of the guinea-pig was supplied, primarily, by the maxillary artery, via internal ophthalmic arteries and in a small degree by the internal carotids.

To Freisenhausen (1965) and Barone (1996), the rostral choroidal artery was emitted at the base of the brain from the internal carotid artery and reached the roof the III ventricle, forming its choroid plexus, according to what was found in this research. In nutria, the rostral choroidal artery was a collateral branch of the terminal branch of the basilar artery, emitted at the level of its middle third, laterally (Azambuja 2006). In this study in rabbits, the rostral choroidal artery was, in the majority of the cases, collateral branch of the rostral branch of the internal carotid artery.

It was not found in the literature, any indication of the presence of central branches from the rostral branch of the internal carotid artery to the pyriform lobe. However, Araújo \& Campos (2009) cited the presence of thin central branches to the medial area of the pyriform lobe from the terminal branch of the basilar artery, soon before the emission of the middle cerebral artery.

According to De Vriese (1905), the middle cerebral artery was, in the oldest dispositions, phylogenetically a collateral branch of the rostral terminal branch of the internal carotid artery. But in the higher vertebrates it has lost the collateral appearance, since it was usually so developed or even more than the rostral cerebral artery. That was the case in the rabbit, where the middle cerebral artery was the main collateral branch of the rostral branch of the internal carotid artery, also in agreement with Freisenhausen (1965) and Barone (1996), which described it as a thick caliber vessel, with several ramifications to the convex surface of the brain. Freisenhausen (1965) also reported that the middle cerebral artery made an anastomosis with branches from the caudal and rostral cerebral arteries, exactly as found in the present study.

In the studies of Ocal \& Ozer (1992) in guinea-pig, Araújo \& Campos (2005) in chinchilla, Azambuja (2006) in nutria and Araújo \& Campos (2009) also in chinchilla, the middle cerebral artery was always presented single. In capybara (Reckziegel et al. 2001), the middle cerebral artery was, normally single, but also was double, as in the rabbits studied.

In rabbits, the main axis of the middle cerebral artery emitted to the cerebral lateral fossa and olfactory trigonous rostral central and perforating branches to the cerebral lateral fossa. Caudally, it emitted caudal central branches to the pyriform lobe, in agreement with the finding of Araújo \& Campos (2009) in chinchilla, where three caudal central branches of the middle cerebral artery were responsible for the irrigation of the pyriform lobe, in the majority of the cases, in both antimeres. However, in rabbits, the territorial area of the pyriform lobe was divided and vascularized, in part by central branches originated from the rostral branch of the internal carotid artery and in part by caudal central branches of the middle cerebral artery.
According to De Vriese (1905), Freusenhausen (1965), Barone (1996) and Kapoor et al. (2003), the rostral cerebral artery in rabbits was a middle caliber vessel and terminal branch of the internal carotid artery, which united with the opposite antimere, rostrally to form a single vessel, the rostral communicating artery. In guinea-pig, the rostral cerebral arteries also united to form a single median vessel (Ocal \& Ozer 1992), as well as in the mouse and rat (Lazorthes et al. 1976); however, in these last two, the authors did not consider a single vessel as a communicating artery.

In chinchilla, the rostral cerebral artery was a present vessel and well-developed in almost every samples, except for two animals, which presented as a vestigial vessel (Araújo \& Campos 2005). But in nutria, the rostral cerebral artery was present as a single vessel and well-developed, in $86.7 \%$ of the samples to the right and in $100 \%$ to the left. In $10 \%$ of the cases, it was presented as a double vessel and in $3.3 \%$ was absent (Azambuja 2006). In the rabbits analyzed, it was not observed cases of absence of the rostral cerebral artery.

De Vriese (1905) reported that in every mammal the rostral cerebral arteries anastomosed among them, either by forming a single median artery, which contours the corpus callosum's knee bifurcating soon, or by the union of one or more transversal arteries, like found in the present study. But to Freisenhausen (1965) and Lazorthes et al. (1976), there was not a real rostral communicating artery in the rabbit, but an inconstant anastomosis between the two rostral cerebral arteries. While, for Araújo \& Campos (2005) and for Azambuja (2006), the rostral inter-hemispheric artery was a single median vessel, originated from the rostral cerebral artery, from only one antimere.

Reckziegel et al. (2001) reported that in $10 \%$ of the capybaras studied there was an absence of the rostral communicating artery due to an atrophy of one of the rostral cerebral arteries. Barone (1996) also reported the absence of the rostral communicating artery in rabbits, making the two rostral cerebral arteries independent, as the same found in $6.7 \%$ of the rabbits analyzed.

In chinchilla, the medial and lateral arteries of the olfactory bulb were collateral branches of the rostral cerebral artery, with the rostral inter-hemispheric artery, ending as internal ethmoidal artery (Araújo \& Campos 2005). But in nutria, the lateral and medial arteries of the olfactory bulb, with the medial branch of the rostral cerebral artery, were collateral branches of the rostral cerebral artery and ended as internal ethmoidal artery (Azambuja 2006). The medial and lateral arteries of the olfactory bulb were emitted, in the rabbit, by the rostral communicating artery, and the olfactory bulb was vascularized, in its majority, by the external ethmoidal artery, branch of the maxillary artery. These two arteries didn't have the same territorial importance as in the other animals cited above.

In chinchilla, to Araújo \& Campos (2005) and in nutria to Azambuja (2006), the internal ethmoidal artery was a branch from the rostral cerebral artery, after the emission of the medial and lateral arteries of the olfactory bulb. In $6.7 \%$ of the brains in nutria, the right internal ethmoidal artery was double and a branch of the medial branch of the 
left rostral cerebral artery. But in chinchilla, the internal ethmoidal artery was a branch from the rostral cerebral artery after the emission of the medial artery of the olfactory bulb, and in a few cases, was branch from the internal ethmoidal artery, in the opposite antimere. In the rabbit, the internal ethmoidal artery was absent in the majority of the cases, and when present, it was single and branch from the rostral communicating artery.

According to De Vriese (1905), the caudal communicating arteries were the terminal branches of the internal carotid arteries, of extremely variable calibers and, also considered as collateral branches of the carotid arteries, based on its appearance in higher mammals. Morphologically, they had the same meaning as terminal branches. In the case of the rabbit, the caudal terminal branch of the internal carotid artery (caudal communicating artery) projected caudally with a slight lateral divergence, following the medial limit of the pyriform lobe until it reached the terminal branch of the basilar artery of the same antimere and formed the caudal cerebral artery (Freisenhausen 1965, Lazorthes et al. 1976, Barone 1996).

Still for De Vriese (1905), the caudal cerebral artery, was, in the primitive stadium, a caudal terminal collateral branch of the internal carotid artery, and in a most recent stadium, it formed the limit of the anastomosis between the caudal branch of the internal carotid artery and the division branch of the basilar artery. Later, it was the end of the division branch from this last, and in a most recent stadium, the caudal cerebral artery was collateral of the division branch from the terminal branches of the basilar artery. Morphologically, so, the caudal cerebral artery belonged to the carotid system. Only, the sequence of secondary vascular modifications made it seam to belong to the vertebral domain. In the studied rabbits, the caudal cerebral artery received a blood influx from both systems, carotid and vertebrobasilar, being impossible to configurate it as collateral branch of the caudal branch of the internal carotid artery, nor as terminal branch from one of the two vessels, that is, from the caudal branch of the internal carotid artery or terminal branch of the basilar artery. Here, both systems flow together and formed the caudal cerebral artery. Freisenhausen (1965) reported that the caudal cerebral artery was emitted from the bifurcation of the basilar artery, at the level of the interpeduncular fossa and irrigated the mesencephalon, the diencephalon with the pineal body, the choroid plexus of the III ventricle, occipital cortex, the splenium of the corpus callosum and the hippocampus, besides emitting lateral branches to the cerebellum, through the rostral cerebral artery. But for Kapoor et al. (2003), in their study with 25 rabbits, reported that the basilar artery bifurcated into two caudal cerebral arteries, which united to the internal carotid artery by the caudal communicating artery. In guinea-pig, the small caudal communicating arteries projected caudally and united directly at the rostral end of the basilar artery and formed a distinct "V". The caudal cerebral arteries had an asymmetric origin at the rostral end of the basilar artery (Ocal \& Ozer 1992). Either in capybara, as in chinchilla and nutria, the caudal cerebral artery was originated as collateral branch of the terminal branch of the basilar artery (Reckziegel et al. 2001, Araújo \& Campos 2005, Azambuja 2006).

In nutria (Azambuja 2006), in the majority of the pieces, the caudal cerebral artery was single and emitted the rostral tectal artery, as in the studied rabbits. But in chinchilla (Araújo \& Campos 2005), the caudal cerebral artery was also single in the majority of the preparations, to the right, and a multiple vessel to the left; however, the rostral tectal artery was emitted from the terminal branch of the basilar artery, between the rostral cerebellar and the caudal cerebral arteries. This change was also seen in the present study in some cases of duplicity of the caudal cerebral artery, where the most caudal component was the isolated rostral tectal artery.

In capybara, to Reckziegel et al. (2001), the caudal cerebral artery was single, double and triple. In the analyzed rabbits, also the single, double and triple caudal cerebral artery was present. The same was observed in chinchilla, where cases of double and triple vessels were seen in both antimeres (Araújo \& Campos 2005); as the same in nutria, where cases of duplicity of the caudal cerebral artery were present (Azambuja 2006).

In the cases of duplicity of the caudal cerebral artery in nutria, the most caudal vessel was always of a smaller caliber and formed the rostral tectal artery (Azambuja 2006). The same variation was observed, in some of the samples, in the rabbit, as well as it was also found animals where the most caudal component was a trunk that originated the rostral tectal and diencephalic arteries.

To Freisenhausen (1965) in rabbits, Reckziegel et al. (2001) in capybara, Araújo \& Campos (2005) in chinchilla and Azambuja (2006) in nutria, the vertebral artery was a thick caliber vessel in the majority of the preparations, and the anastomosis of its terminal branches formed the basilar artery, at the base of the medulla oblongata.

In rabbits, the ventral spinal artery was formed in the majority of the cases by branches from the right and left vertebral arteries, in agreement with Reckziegel et al. (2001) and with Azambuja (2006). But, in the research of Araújo \& Campos (2005), the ventral spinal artery was formed in the majority of the cases just by the left vertebral artery.

The basilar artery was presented as a thick caliber vessel and straight in the majority of the preparations (Barone 1996, Reckziegel et al. 2001, Araújo \& Campos 2005, Azambuja 2006). Azambuja (2006) described in the basilar artery the presence of an "island" formation in some nutrias, having the same been observed in some of the analyzed rabbits.

Barone (1996) reported that the collateral branches of the basilar artery vascularized the most rostral third of the medulla oblongata and the pons in the rabbit. And that among the vessels originated from it, the caudal cerebellar artery with its labyrinthic branch and the trigeminal artery were the most important branches. In capybara (Reckziegel et al. 2001), the main collateral branches of the basilar artery were the caudal and middle cerebellar arteries. In chinchilla, (Araújo \& Campos 2005), the larger caliber collateral branches of the basilar artery were the caudal 
cerebellar, trigeminal and rostral cerebellar arteries, most caudal vessel. While in nutria (Azambuja 2006), the collateral branches of larger caliber of the basilar artery were the caudal cerebellar, middle cerebellar and trigeminal arteries.

To Freisenhausen (1965), the caudal cerebellar arteries were originated approximately in the middle of the basilar artery, irrigated the cerebellum, the same was observed in capybara, chinchilla and nutria (Reckziegel et al. 2001, Araújo \& Campos 2005, Azambuja 2006). In the analyzed rabbits, the caudal cerebellar artery, besides irrigating the caudoventral lobules of the cerebellum, emitted a labyrinthic artery to the internal ear (Barone 1996).

In capybara (Reckziegel et al. 2001) and chinchilla (Araújo \& Campos 2005), in the majority of the cases, the caudal cerebellar artery was double. In nutria (Azambuja 2006), the caudal cerebellar artery presented cases of duplicity and triplicity. The caudal cerebellar artery in rabbits was single, being possible cases of duplicity and triplicity.

The rabbit did not present the middle cerebellar artery, like observed in capybara and nutria (Reckziegel et al. 2001, Azambuja 2006).

The basilar artery bifurcated on its terminal branches, right and left, at the level of the sulcus that separates the cerebral peduncles of the pons, in a divergent angle of $\pm 90^{\circ}$ (Araújo \& Campos 2005, Azambuja 2006), and anastomosed with the caudal communicating artery (caudal branch of the internal carotid artery), forming with this the caudal cerebral artery. Its main collateral branch was the rostral cerebellar artery. In capybara, the formation of the terminal branches of the basilar artery also occurred at the level of the sulcus that separates the pons of the cerebral peduncles, but in an approximate angle of $55^{\circ}$. Close to the bifurcation, it emitted the caudal cerebellar artery, and soon after the emergence of the oculomotor nerve, the caudal cerebral artery (Reckziegel et al. 2001).

In capybara (Reckziegel et al. 2001), the rostral cerebellar artery was double in the majority of the cases, originated from the same place as in the rabbit. But in chinchilla (Araújo \& Campos 2005), the rostral cerebellar artery, its most caudal component, was originated from the basilar artery, close to its bifurcation, in the majority of the pieces; and the most rostral component of the rostral cerebellar artery was also present, as collateral branch of the terminal branch of the basilar artery. While in nutria (Azambuja 2006), the rostral cerebellar artery was most of the time single and collateral branch of the terminal branch of the basilar artery. The rostral cerebellar artery was, in rabbits, a large caliber vessel, originated from the terminal branch of the basilar artery, and in the most of the time double to the right (53.3\%) and single to the left (63.3\%).

To Freinsenhausen (1965), the rostral cerebellar artery was double several times, and a branch of the caudal cerebral artery. This author considered the caudal cerebral artery a vessel which bifurcated from the basilar artery, and this did not present its terminal branches, right and left. The rostral cerebellar artery divided into a rostral branch, which supplied the caudal and rostral colliculus of the mesencephalic tectum and the cerebellum; and a caudal bran- ch that irrigated only the caudal colliculus and the rostral surface of the cerebellum. In the rabbit in this research, as in capybara (Reckziegel et al. 2001), in chinchilla (Araújo \& Campos 2005) and in nutria (Azambuja 2006), the rostral cerebellar artery was collateral branch of the terminal branch of the basilar artery. The rostral branch of the rostral cerebellar artery to Freisenhausen (1965) has the same behavior as the artery denominated by us as rostral tectal artery, branch of the caudal cerebral artery; but the caudal branch of the rostral cerebellar artery to Freinsenhausen (1965), seams to be the caudal tectal artery, branch of the rostral cerebellar artery, that vascularized the caudal colliculus.

For Tandler (1898), the blood supply sources to the cerebral arterial circle could occur in every different type between two extremes, that is, the circle's supply done only by the vertebral arteries like in Rhinolophus, Chiromys and Lemur or in an extreme opposite situation, where the cerebral arterial circle was originated only by the internal carotid artery, or by the "rete mirabile" formed by this, like for example, in Artiodactyla.

But for De Vriese (1905), the cerebral arterial circle can be classified in three different types: type I, where the cerebral blood supply was done exclusively by the internal carotid arteries; type II, where the carotid system and the vertebrobasilar system participated together in the irrigation to the brain; and type III, where just the vertebrobasilar system participated in the encephalic irrigation. According to the author, based on phylogenetical data, the cerebral arterial circle of the mammals was irrigated by the internal carotid arteries, kept the most primitive characteristics; and that one which was exclusively supplied by the vertebral arteries, presents more recent characteristics. The cerebral arterial vascularization of the rabbit was equally supplied by two systems, the vertebrobasilar and the carotid, fitting on type II of De Vriese (1905) and in agreement with the description of Freisenhausen (1965), because both systems came together to form the caudal cerebral artery. But the cerebral arterial circle of chinchilla (Araújo \& Campos 2005) and nutria (Azambuja 2006) were classified as type III, where only the vertebrobasilar system participated in the cerebral irrigation. The cerebral arterial circle of capybara (Reckziegel et al. 2001) was also classified as type III, however, morphofunctionally the anastomosis presented in this animal, between the maxillary and the internal ophthalmic arteries or between the maxillary artery and the terminal branch of the basilar artery, could serve as compensatory alternative blood supply.

According to Tandler (1898), in every examined mammals the cerebral arterial circle was completely closed. In the case of the rabbit, the cerebral arterial circle was caudally closed in every preparation (Reckziegel et al. 2001, Araújo \& Campos 2005, Azambuja 2006).

But rostrally, the cerebral arterial circle in chinchilla (Araújo \& Campos 2005) and nutria (Azambuja 2006) was opened in the majority of the samples. While in capybara (Reckziegel et al. 2001), the cerebral arterial circle was rostrally closed in almost every samples, with a few cases in which it was opened, like in rabbits. This finding disagre- 
es with the reports found by several authors; because they described that the cerebral arterial circle of the rabbit was always rostrally closed (Freisenhausen 1965, Lazortheset al. 1976, Kapoor, Kak \& Singh 2003). However, Barone (1996) observed that in every ten rabbits, the cerebral arterial circle was incomplete, due to the absence of the rostral communicating artery; a proved fact in the present study.

According to De Vriese (1905), the cerebral arterial circles classified as type II could present subtypes alpha, beta and gamma, where the vascular cooperation between the carotid and vertebrobasilar systems were altered, with the most frequent participation of the vertebrobasilar system, advancing into the carotid system's vascular territory. So, when the rostral cerebellar artery clearly was a direct terminal branch of the terminal branch of the basilar artery, the classification was of subtype II alpha, as in some carnivores. When the caudal cerebral artery was clearly a direct continuation of the terminal branches of the basilar artery, the subtype was II beta, as in humans. But when the terminal branch started to have bloody flow towards the rostral branch of the internal carotid artery, which already presented some atrophy, it was classified as subtype II gamma, as in rats.

In this study, it was found that the caudal cerebral artery received bloody flow from both systems, and because of that, the cerebral arterial circle of the rabbit was classified as subtype II alpha, with beta tendency.

\section{REFERENCES}

Albuquerque J.F.G., Souza W.M., Fonseca M.A.G., Bastos C.M.C. \& Carregal R.D. 1987. Contribuição ao estudo dos colaterais calibrosos do arco aórtico no coelho (Oryctolagus cuniculus Linnaeus, 1758) da raça Nova Zelândia. Ars Vet. 3:1-4.

Alcântara M.A. 1992. Estudo anatômico das artérias da base do encéfalo de cães (Canis familiaris Linnaeus, 1758). Dissertação de Mestrado em Anatomia Animal, Faculdade de Medicina Veterinária e Zootecnia, Universidade de São Paulo, São Paulo, SP. 134p.

Angell-James J.E. 1974. Variations in the vasculature of the aortic arch and its major branches in the rabbit. Acta Anat. 87:283-300.

Araújo A.C.P. \& Campos R. 2005. A systematic study of the brain base arteries and their blood supply sources in the chinchilla (Chinchilla lanigera Molina, 1782). Braz. J. Morphol. Sci. 22(4):221-232.

Araújo A.C.P. \& Campos R. 2009. Systemation, distribuition and territory of the Middle Cerebral Artery on the brain surface in Chinchilla (Chinchilla lanigera). Anat. Histol. Embryol. 38:12-17.

Araújo A.C.P., Oliveira J.C.D. \& Campos R. 2004. Ramos colaterais do arco aórtico e suas principais ramificações em chinchila (Chinchilla lanigera). Revta Port. Ciênci. Vet. 99(549):53-58.

Atalar Ö., Yilmaz S., Burma 0. \& Ílkay E. 2003. The macroanatomical investigations on the aortic arch in Porcupines (Hystrix cristata). Anat. Histol. Embryol. 32:367-369.

Azambuja R.C. 2006. Sistematização das artérias da base do encéfalo e suas fontes de suprimento sanguíneo em nutria (Myocastor coypus). Dissertação de Mestrado em Morfologia, Cirurgia e Patologia Animal especialidade Anatomia Animal, Faculdade de Veterinária, Universidade Federal do Rio Grande do Sul, Porto Alegre, RS. 150p.
Barone R. 1996. Anatomie Comparée des Mammifères Domestiques: Angiologie. Vigot, Paris. 904p.

Casals J.B., Pieri N.C., Feitosa M.L., Ercolin A.C., Roballo K.C., Barreto R.S., Bressan F.F., Martins D.S., Miglino M.A. \& Ambrósio C.E. 2011.The use of animal models for stroke research: a review. Comp Med. 61(4):305313.

Campos R., Araújo A.C.P. \& Azambuja R.C. 2010. Ramos colaterais do arco aórtico e suas principais ramificações em nutria (Myocastor coypus). Acta Scient. Vet. 38(2):139-146.

Campos R., Ferreira N. \& Marrone A.C.H. 1995. A systematic study of encephalic blood supply in Gallus gallus. J. Anat. Embryol. 100:111-121.

Carvalho A.D. \& Campos R. 2011. A sytematic study of the brain base arteries in the turkey (Meleagris gallopavo). Pesq. Vet. Bras. 31(Supl.1): 39-46.

Culau P.O.V., Reckziegel S.H., Lindemann T., Araújo A.C.P. \& Balzaretti F. 2007. Colaterais do arco aortic da capivara (Hydrochoerus hydrochaeris). Acta Scient. Vet. 35(1):89-92.

Depedrini J.S. \& Campos R. 2004. Systematic of the brain base arteries in pampas fox (Dusicyon gymnocercus). Braz. J. Morphol. Sci. 20(3):181188.

De Vriese B. 1905. Sur la signification morphologique des artères cérébrales. Archs Biol. 21:357-457.

Ferreira C.G. 1998. Estudo anatômico das artérias da base do encéfalo de suínos (Sus scrofa domesticus Linnaeus, 1758). Dissertação de Mestrado em Anatomia, Faculdade de Medicina Veterinária e Zootecnia, Universidade de São Paulo, São Paulo, SP. 98p.

Freisenhausen H. 1965. Gefässanordnung und Kapillardichte in Gehirn des Kaninchens. Acta Anat. 62:539-562.

Kabak M. \& Haziroglu R.M. 2003. Subgross investigation of vessels originating from arcus aortae in Guinea-pig (Cavia porcellus). Anat. Histol. Embryol. 32:362-366.

Kapoor K., Kak V.K. \& Singh B. 2003. Morphology and comparative Anatomy of circulus arteriosus cerebri in mammals. Anat. Histol. Embryol. 32:347-355.

Lazorthes G., Gouazé A. \& Salamon G. 1976. Anatomie comparée du système artériel de l'encéphale, p.14-30. In: Ibid. (Eds), Vascularization et Circulation de l'Encéphale. Masson, Paris.

Lindemann T., Reckziegel S. \& Campos R. 2000. A systematic study of brain base arteries in the opossum (Didelphis albiventris). Braz. J. Morphol. Sci. 17:35-41.

Magalhães M., Albuquerque J.F.G., Oliveira M.F., Papa P.C. \& Moura C.E.B. 2007. Ramos do arco aórtico em mocó (Kerodon rupestris). Revta Port. Ciênc. Vet. 10(561/562):49-52.

Nazer M.B. \& Campos R. 2011. Sytematization of the brain base arteries in ostrich (Struthio camelus). J. Morphol. Sci. 21(4):268-274.

Nomina Anatomica Veterinaria 2005. International Committee on Veterinary Gross Anatomical Nomenclature - ICVGAN. $5^{\text {th }}$ ed. World Association on Veterinary Anatomist, New York. 198p.

Ocal M.K. \& Ozer M. 1992. The circulus arteriosus cerebri in guinea pig. Annals of Anatomy 174:259-260.

Oliveira F.S., Machado M.R.F., Miglino M.A. \& Nogueira T.M. 2001. Gross anatomical study of the aortic ARC branches of the paca (Agouti paca Linnaeus, 1766). Braz. J. Vet. Res. Anim. Sci. 38(3):103-105.

Reckziegel S.H., Lindemann T. \& Campos R. 2001. A systematic study of the brain base arteries in capybara (Hydrochoerus hydrochaeris). Braz. J. Morphol. Sci. 18(2):104-110.

Tandler J. 1898. Zur vergleichenden Anatomie der Kopfarterien bei den Mammalia. Denkschriften der Akademie der Wissenschaften 67:677779. 